\title{
Evaluation of operation and management of Luocheng small municipal wastewater treatment plant
}

\author{
Qiaoquan Wei ${ }^{1}$, Guanwen Cheng, ${ }^{1,}$, Bangzhou Sun $^{2,}$, , Liao Zhang ${ }^{1}$, Yuling Zhang ${ }^{1}$, , Jiangzhou Wei ${ }^{2}$, Xing Yang ${ }^{2}$ \\ ${ }^{1}$ College of Environmental Science and Engineering, Guilin University of Technology, Guilin Guangxi 541004, China \\ ${ }^{2}$ Guirun Environmental Protection Technology Co., Ltd, Nanning Guangxi 530201, China
}

\begin{abstract}
Operation efficiency, effect and operation energy consumption are the main basis for the evaluation of the operation and management level of wastewater treatment plant. The statistics of the operation data of the small municipal wastewater treatment plant in Luocheng County show that the operation rate of the facility is high, and the treated effluent reaches the Level A standard of the "Discharge standard of pollutants for municipal wastewater treatment plant" (GB18918-2002), and the various evaluation indicators of the urban wastewater treatment plant basically normal. However, the average operating load of some municipal wastewater treatment plant has not reached the index requirement for the operation period of production, and the load rates of $\mathrm{COD}_{\mathrm{Cr}}$ and $\mathrm{NH}_{4}{ }^{+}-\mathrm{N}$ are mostly below $60 \%$, and wastewater treatment plant unit wastewater volume, unit $\mathrm{CODCr}_{\mathrm{C}}$ and $\mathrm{NH}_{4}{ }^{+}-\mathrm{N}$ load energy consumption is high. The reason is that the water quality of the design of the micro-municipal wastewater treatment plant is not reasonable, the construction scale is too large, and the operation fails to adopt effective management and control technology measures.
\end{abstract}

\section{Introduction}

In order to earnestly promote the "Action plan for prevention and control of water pollution", and according to the requirements of "Technical specification for management of municipal wastewater treatment plant operation" (HJ2038-2014), we conduct systematic research and verification on the wastewater treatment, equipment and facility maintenance, analysis and testing, information recording and archiving, safety supervision, accessory configuration and consumables procurement, equipment and facility matching, and management standardization of the seven wastewater treatment plant in Luocheng County, and refer to "Standard for operation and maintenance quality assessment of municipal wastewater treatment plant" (CJJ/T228-2014) and "Technical specification for operation, maintenance and safety of municipal wastewater treatment plant" (CJJ602011), conducts evaluation and assessment of the operation of each wastewater treatment plant, with a view to providing a basis for the continuous operation management and improvement of these small municipal wastewater treatment plant.

\section{Basic overview of Luocheng small municipal wastewater treatment plant}

Luocheng Mulao Autonomous County is located in the northeast of Hechi City. At present, the county has built
Luocheng County wastewater treatment plant and Longan, Siba, Huaiqun, Tianhe, Huangjin and Xiao Changan municipal wastewater treatment plant, with a total of 22 employees, and its operation management personnel composition is shown in table 1. Mainly to young and middle-aged, college degree three people, technical secondary school education 5 people, no technical title. Luocheng County wastewater treatment plant is a CASS process, put into operation in 2010; Longan and Siba municipal wastewater treatment plant are IBR and $\mathrm{A}^{2} / \mathrm{O}$ processes, which were put into operation in 2015; Huaiqun, Tianhe, Huangjin and Xiao Changan municipal wastewater treatment plant are all DMBR processes, put into operation in 2018. Wastewater treatment process types are various. According to the operation process, the effluent treated by Luocheng and Longan wastewater treatment plant implements the Level B standard of the "Discharge standard of pollutants for municipal wastewater treatment plant" (GB18918-2002), other five municipal wastewater treatment plant implement the Level A standard. The discharge standard of pollutants is different. Differences in economic development lead to different construction scales. The construction scale of Luocheng municipal wastewater treatment plant is 15000 $\mathrm{m}^{3} / \mathrm{d}$, the construction scale of Longan municipal wastewater treatment plant is $2000 \mathrm{~m}^{3} / \mathrm{d}$, and the other municipal wastewater treatment plant is $500 \mathrm{~m}^{3} / \mathrm{d}$. 
Tab 1. Wastewater treatment plant personnel age and education.

\begin{tabular}{|c|c|c|c|c|c|c|c|}
\hline \multirow{2}{*}{ Project } & \multicolumn{3}{|c|}{ Age } & \multicolumn{4}{c|}{ Education } \\
\cline { 2 - 8 } & $25-34$ & $35-44$ & $45-54$ & College degree & Secondary education & High school diploma & Junior high school and below \\
\hline Number & 7 & 11 & 4 & 3 & 5 & 2 & 12 \\
\hline Percent & 31.82 & 50.00 & 18.18 & 13.64 & 22.73 & 9.09 & 54.55 \\
\hline
\end{tabular}

\section{Operation evaluation and analysis of Luocheng small municipal wastewater treatment plant}

\subsection{Evaluation of operation efficiency and effect of wastewater treatment facilities of wastewater treatment plant in small municipal}

(1) High operating rate of facilities. From January to July 2019, all the wastewater treatment plant in small municipal were in normal operation, the operating rate of the facilities was $100 \%$, and there was no outage of facilities such as power outages and failures.

(2) Municipal wastewater treatment plant has low operating load rates. Figure 1 shows the statistical results of the inflow operation load rate of each wastewater treatment plant from April to June (individual May to July). It can be seen from the figure1: (1) the average daily operating load rate of Luocheng County's urban wastewater treatment plant is above $120 \%$, while the average daily operating load rate of municipal wastewater treatment plant is around $50 \%$. The average operating load rate of municipal wastewater treatment plant is significantly lower than that of urban wastewater treatment plant, and lower than that of other urban wastewater treatment plant in Guangxi ${ }^{[1]}$. (2) the average daily treatment capacity of 6 municipal wastewater treatment plant is $2523 \mathrm{~m}^{3} / \mathrm{d}$, which is $56 \%$ of the construction scale. Among them, the average operating load of Longan and Siba wastewater treatment plant is 55\% and $76 \%$, respectively, which did not reach the $80 \%$ operation load target for 3 years of operation; The average operation load of Xiao Changan wastewater treatment plant is $66.2 \%$, reached $60 \%$ of the operating load target for 1-3 years of operation, while the average operating load of wastewater treatment plant in Huaiqun, Tianhe and Huangjin municipal are $38 \%, 56 \%$, and $48.8 \%$, respectively, failing to meet the operating load requirement of $60 \%$ for $1-3$ years of production. Municipal wastewater treatment plant is mostly in lowload operation. In recent years, the county's real estate has developed rapidly, and municipal residents with good economic conditions have come to the county to buy property. The total urban population and the total amount of wastewater discharged have continued to increase, causing Luocheng urban wastewater treatment plant to operate overloaded; The terrain is mostly dominated by rocks and mountain creeks, most residential houses are built along both sides of the road and some residential houses have a high top and low topography, which makes it difficult for the drainage pipe network coverage to reach $90 \%$, resulting in a pipe network household rate and wastewater network rate is reduced. In addition, when young and middle-aged people go out to work, the actual daily water consumption of villages and municipal is about $100 \mathrm{~L} / \mathrm{d}$, which is lower than the designed wastewater discharge number and the per capita water consumption of $150 \mathrm{~L} / \mathrm{d}$. These have an impact on the operation load of micro-municipal wastewater treatment plant the operation of wastewater pumps, mixed liquid reflux pumps, fans and other equipment and the hydraulic residence time control of facilities such as biochemical pools, secondary sedimentation tanks or membrane pools have a negative impact.

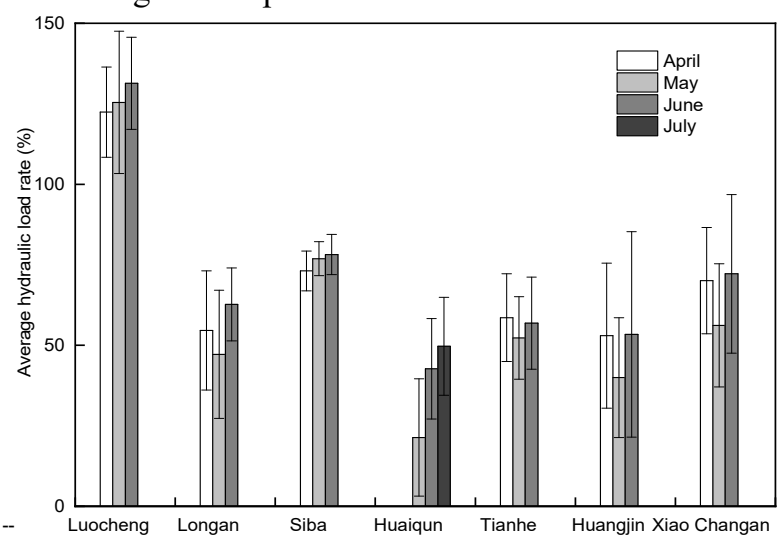

Fig. 1. The operation load of Luocheng County small municipal wastewater treatment plant.

(3) The influent water quality concentration is uneven, the effluent water quality is very close, and the reduction of $\mathrm{COD}_{\mathrm{Cr}}$ and $\mathrm{NH}_{4}{ }^{+}-\mathrm{N}$ is close to the limit. Table 2 and table 3 are the statistical results of the monthly average influent and monthly average effluent of the municipal wastewater treatment plant from April to June 2019. It can be seen from the table: (1) the actual inlet water quality of wastewater treatment plant in small municipal differs greatly. The TP concentration of all wastewater treatment plant is low; The wastewater treatment plant of Tianhe, Longan and Xiao Changan have livestock and poultry farming, silk reeling and slaughter wastewater discharge respectively, the influent $\mathrm{COD}_{\mathrm{Cr}}$ and $\mathrm{NH}_{4}{ }^{+}-\mathrm{N}$ concentrations are high and fluctuate greatly. Luocheng municipal wastewater treatment plant may have surface water infiltration because part of the wastewater pipe network is laid along the river bank. There may also be similar situations in the Siba and Huangjin wastewater treatment plant, resulting in a slightly lower influent water quality concentration; The effluent $\mathrm{COD}_{\mathrm{Cr}}$ of the treatment plant is mostly around $10 \mathrm{mg} / \mathrm{L}$, and the effluent 
Tab 2. A list of design inlet and average inlet water quality of Luocheng County small municipal wastewater treatment plant (mg/L)

\begin{tabular}{|c|c|c|c|c|c|c|c|c|c|c|c|}
\hline $\begin{array}{c}\text { Wastewater Treatment } \\
\text { Works }\end{array}$ & \multicolumn{2}{|c|}{ Luocheng } & \multicolumn{2}{|c|}{ Longan } & \multicolumn{2}{c|}{ Siba } & \multicolumn{5}{c|}{ The four others municipal } \\
\hline Influent index & Design & Actual & Design & Actual & Design & Actual & Design & Huaiqun & Tianhe & Huangjin & Xiao Changan \\
\hline $\mathrm{COD}_{\mathrm{Cr}}$ & $\leq 300$ & 130 & $\leq 350$ & 178 & $\leq 250$ & 91 & $\leq 140$ & 110 & 295 & 116 & 147 \\
\hline $\mathrm{SS}$ & $\leq 180$ & - & $\leq 220$ & - & $\leq 250$ & - & $\leq 80$ & - & - & - & - \\
\hline $\mathrm{NH}_{4}{ }^{+}-\mathrm{N}$ & $\leq 30$ & 12.23 & $\leq 30$ & 15.98 & $\leq 30$ & 15.45 & $\leq 18$ & 32.18 & 49.00 & 21.64 & 35.20 \\
\hline $\mathrm{TN}$ & $\leq 40$ & - & $\leq 40$ & - & $\leq 45$ & - & $\leq 30$ & - & - & - & - \\
\hline $\mathrm{TP}$ & $\leq 3.5$ & 0.90 & $\leq 4$ & 1.86 & $\leq 5$ & 1.00 & $\leq 2$ & 1.47 & 2.04 & 1.91 & 2.00 \\
\hline
\end{tabular}

Tab 3. The monthly average effluent $\mathrm{COD}_{\mathrm{Cr}}$ and $\mathrm{NH}_{4}{ }^{+}-\mathrm{N}$ of Luocheng County small municipal wastewater treatment plant (mg/L)

\begin{tabular}{|c|c|c|c|c|c|c|c|c|}
\hline & Months & Luocheng & Longan & Siba & Huaiqun $^{*}$ & Tianhe & Huangjin & Xiao Changan \\
\hline \multirow{3}{*}{$\mathrm{COD}_{\mathrm{Cr}}$} & 4 & 24 & 16 & 9 & 6 & 9 & 9 & 8 \\
\cline { 2 - 10 } & 5 & 25 & 3 & 9 & 5 & 9 & 7 & 8 \\
\cline { 2 - 10 } & 6 & 29 & 4 & 9 & 6 & 9 & 10 & 8 \\
\hline \multirow{3}{*}{$\mathrm{NH}_{4}{ }^{-}-\mathrm{N}$} & 4 & 0.54 & 1.20 & 0.67 & 0.93 & 0.33 & 0.34 & 0.45 \\
\cline { 2 - 10 } & 5 & 0.41 & 1.50 & 0.71 & 0.96 & 0.53 & 0.18 & 0.08 \\
\hline
\end{tabular}

*Note: Huaiqun municipal wastewater treatment plant is May-July operation processing data

$\mathrm{NH}_{4}{ }^{+}-\mathrm{N}$ is mostly below $1 \mathrm{mg} / \mathrm{L}$. The effluent water concentration is low. The treated effluent $\mathrm{COD}_{\mathrm{Cr}}$ and $\mathrm{NH}_{4}{ }^{+}-\mathrm{N}$ all meet the Level A standard of the "Discharge standard of pollutants for municipal wastewater treatment plant" (GB18918-2002). (3) $\mathrm{COD}_{\mathrm{Cr}}$ and $\mathrm{NH}_{4}{ }^{+}-$ $\mathrm{N}$ reductions are closely related to influent water quality concentration (Fig 2). The concentration of influent water is high, and the amount of reduction is also high, and vice versa. Because the influent water quality of small own wastewater treatment plant is generally not high, the operating load is low, the air volume of the fan is small, and the frequency conversion equipment is not selected, and the technical level of the operation and management personnel is limited, and the process and technical parameters cannot be adjusted according to the quality of the influent water. As a result, the hydraulic retention time of each municipal wastewater treatment plant is relatively long, aeration is relatively large, and the concentrations of $\mathrm{COD}_{\mathrm{Cr}}$ and $\mathrm{NH}_{4}{ }^{+}-\mathrm{N}$ in the treated effluent are very low.

(4) The load rates of $\mathrm{COD}_{\mathrm{Cr}}$ and $\mathrm{NH}_{4}{ }^{+}-\mathrm{N}$ in most of small municipal wastewater treatment plants are low. The average $\mathrm{COD}_{\mathrm{Cr}}$ and $\mathrm{NH}_{4}{ }^{+}-\mathrm{N}$ load rates of wastewater treatment plant in small municipal are shown in figure 3. As we can see from the figure 3 , in addition to, the $\mathrm{COD}_{\mathrm{Cr}}$ load rate of the Tianhe municipal wastewater treatment plant exceeding $100 \%$, the $\mathrm{COD}_{\mathrm{Cr}}$ load rates of the wastewater treatment plant of other small municipal are generally less than $60 \%$, Siba and Huangjin municipal are around 30\%; The $\mathrm{NH}_{4}{ }^{+}-\mathrm{N}$ load rates of Tianhe and Xiao Changan wastewater treatment plant are above $120 \%$, but the $\mathrm{NH}_{4}{ }^{+}-\mathrm{N}$ loading rates of wastewater treatment plants in other small municipal are generally below $60 \%$, and only the Longan municipal wastewater treatment plant is about $30 \%$. The pollutant load rates of wastewater treatment plant vary greatly. Table 2 provides the design influent water quality of wastewater treatment plant in small cities and municipal. The design influent water quality indicators of municipal wastewater treatment plant in a county are quite different. These too high or too low design indicators will affect the design process technical parameters (oxygen supply, SV\%, MLSS, etc.), equipment selection and operation control of small municipal wastewater treatment plant (such as aeration and oxygen supply control, return pump operation and Process flow parameters and indicators such as return flow control) and operation management indicators (such as pollutant operation load rate and pollutant operation energy consumption) have a significant impact. Because the actual influent water volume of small municipal

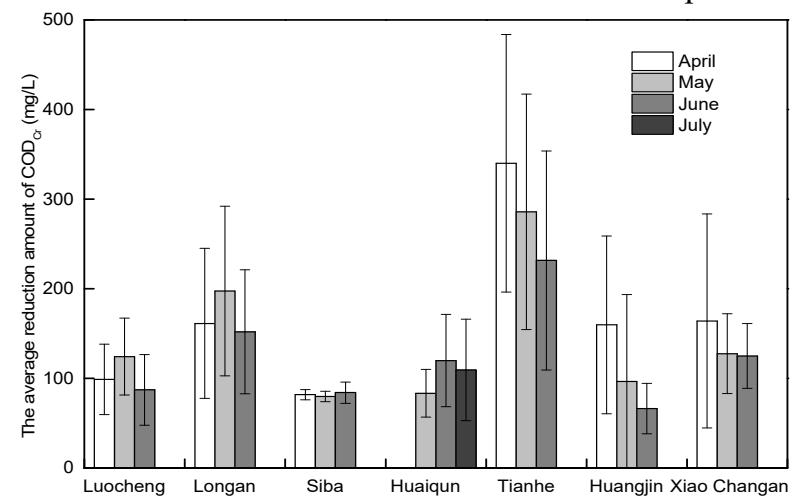




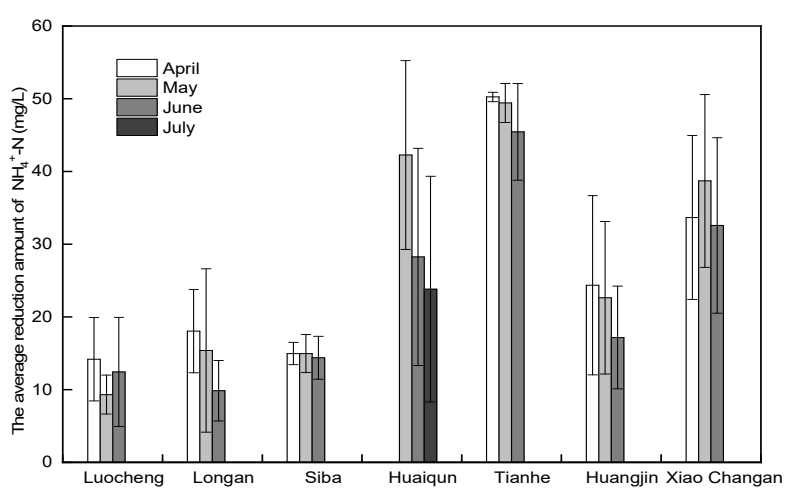

Fig. 2. The average reduction amount of $\mathrm{COD}_{\mathrm{Cr}}$ and $\mathrm{NH}_{4}{ }^{+}-\mathrm{N}$ of Luocheng County small municipal wastewater treatment plant.

wastewater treatment plant is significantly lower than the designed influent water volume, and the influent water quality concentration is often low, when the designed influent water quality concentration is too high, the pollutant load rate will be significantly too low, such as Longan wastewater treatment plant; Even if the Luocheng wastewater treatment plant is operated under superhydraulic load, the actual influent water quality is significantly lower than the designed influent water quality, and its $\mathrm{COD}_{\mathrm{Cr}}$ load rate is also very low. On the contrary, some municipal wastewater treatment plant have low ammonia nitrogen design indicators, even if the operation load of these wastewater treatment plant is not high, it may lead to a significantly higher pollutant load rate, such as the ammonia nitrogen load rate of Tianhe and Xiao Changan wastewater treatment plant; Huaiqun municipal influent ammonia nitrogen concentration of the
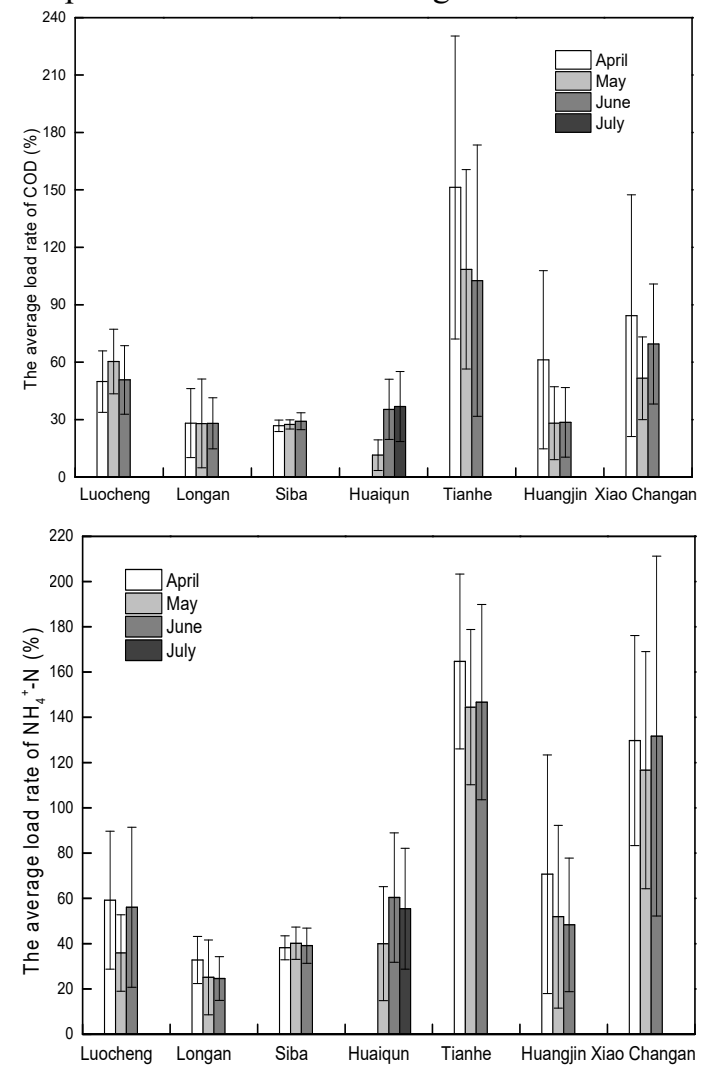

Fig. 3. The average load rate of $\mathrm{COD}_{\mathrm{Cr}}$ and $\mathrm{NH}_{4}{ }^{+} \mathrm{N}$ of Luocheng County small municipal wastewater treatment plant. wastewater treatment plant is not low, and its designed influent concentration is also very low, but its influent water volume is significantly lower than the designed influent water volume (or low operating load rate), so the average ammonia nitrogen load rate is not high. When the design influent water quality concentration and design water quantity of the wastewater treatment plant are unreasonable, it will cause the pollutant load rate of the wastewater treatment plant to deviate significantly, which will have a significant impact on the operation evaluation of the pollutant load rate of the wastewater treatment plant.

\subsection{Evaluation of operation stability and operation energy consumption of municipal wastewater treatment plant}

(1) Facilities and equipment are in good condition. The structures of the municipal wastewater treatment plant are intact and are in normal operating conditions; The wastewater treatment process equipment, power equipment and control equipment are running stably, with good maintenance and maintenance, no overhaul and shutdown records; Complete safety protection devices and sensitive measuring instruments. The equipment and its instruments are operating normally.

(2) Some municipal wastewater biological treatment systems are not stable enough. It can be seen from the figure 4 , the Luocheng urban wastewater treatment plant has a CASS process with a relatively large scale and the aeration tank SV30 is stable; The Longan municipal wastewater treatment plant has an IBR process with a relatively large scale and its aeration tank SV30 fluctuates small. It shows that the operation stability of the suspension biological treatment process is well. In addition to the relatively stable SV30 of Huangjin municipal wastewater treatment plant, the SV30 of the other three municipal wastewater treatment plant fluctuated greatly, indicating that the micro-membrane process wastewater treatment has aeration due to low operating load, low influent substrate concentration, and membrane surface erosion. The high intensity and the low concentration of MLSS in the system suspension cause the reflux of the mixed solution to rapidly change the amount of suspended MLSS in the anoxic and aerobic sections. When the reflux pump is turned on, the MLSS in the aerobic section decreases rapidly, after a period of time, the MLSS in the anoxic section is continuously refluxed, and the MLSS for the separation of mud and water in the membrane pool continues to increase, resulting in strong SV30 fluctuations in the system and reduced system stability. 


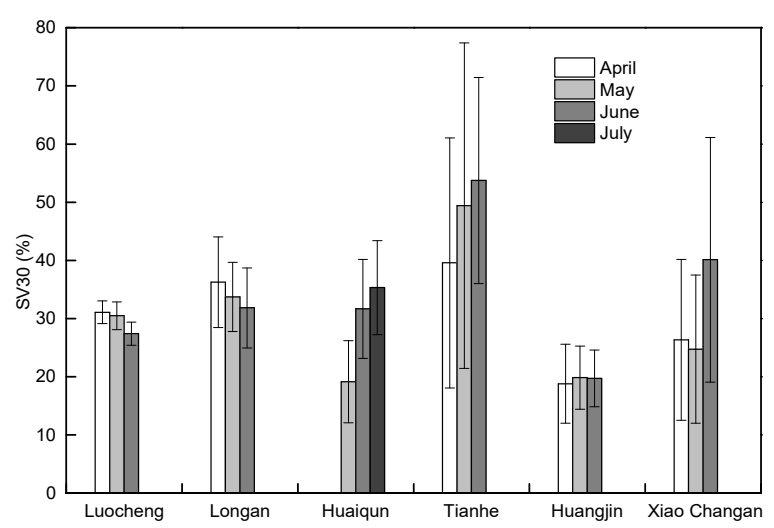

Fig. 4. The SV30 results of Luocheng County small municipal wastewater treatment plant aerobic pool from April to June.

(3) Some operating systems have high energy consumption. It can be seen from the figure 5: (1) The average unit water consumption of Luocheng County's urban wastewater treatment plant is $0.1 \mathrm{~kW} \cdot \mathrm{h} / \mathrm{m}^{3}$, which is slightly lower than the standard B of urban wastewater treatment pollutants discharged by the general activated sludge method, with the low $\mathrm{COD}_{\mathrm{Cr}}$ and $\mathrm{NH}_{4}{ }^{+}-\mathrm{N}$ influent water quality is relatively matched, and the unit wastewater energy consumption index is at a good level; The energy consumption per unit wastewater operation of all other municipal wastewater treatment plant is more than $0.5 \mathrm{~kW} \cdot \mathrm{h} / \mathrm{m}^{3}$, even though the IBR in Longan municipal the technology implements the standard B of pollutant discharge in urban wastewater treatment, and its energy consumption has reached $0.51 \mathrm{~kW} \cdot \mathrm{h} / \mathrm{m}^{3}$. The unit wastewater treatment energy consumption of municipal wastewater treatment plant is significantly higher than the unit wastewater treatment energy consumption of wastewater treatment plant in other cities and municipal in China and Guangxi ${ }^{[2-4]}$; (2) The energy consumption per unit of $\mathrm{COD}_{\mathrm{Cr}}$ load varies, and the energy consumption of $\mathrm{COD}_{\mathrm{Cr}}$ load of Luocheng and Tianhe wastewater treatment plant is below $2.5 \mathrm{~kW} \cdot \mathrm{h} / \mathrm{kg}$, which is in a relatively energy-saving state; However, the energy consumption of $\mathrm{COD}_{\mathrm{Cr}}$ load of Siba and Huaiqun municipal wastewater treatment plant is $5.98 \mathrm{~kW} \cdot \mathrm{h} / \mathrm{kg}$ and above, which is significantly higher than that of domestic urban wastewater treatment plant, which is in a high energy consumption state ${ }^{[2-5]}$.

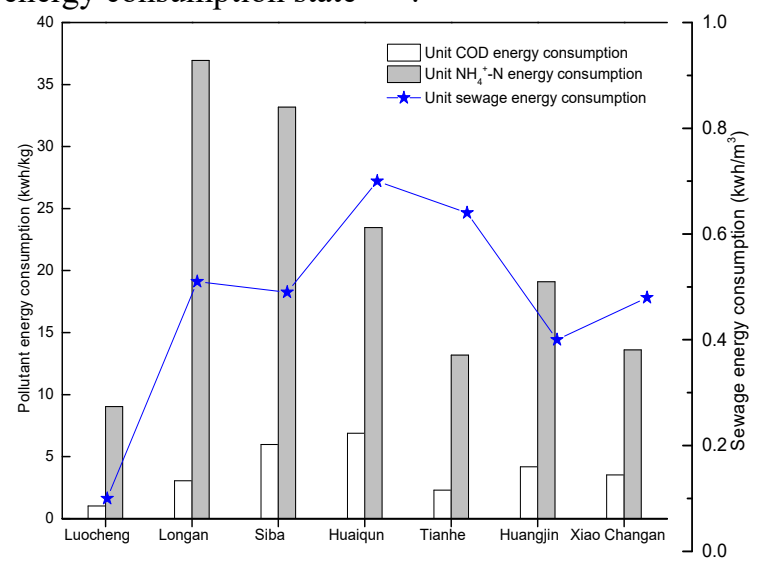

Fig. 5. The operation energy consumption of Luocheng County small municipal wastewater treatment plant.
(4) The energy consumption per unit of $\mathrm{NH}_{4}{ }^{+}-\mathrm{N}$ load varies, and the $\mathrm{NH}_{4}{ }^{+}-\mathrm{N}$ load energy consumption of the three wastewater treatment plant in Luocheng, Tianhe and Xiao changan is below $15 \mathrm{~kW} \cdot \mathrm{h} / \mathrm{kg}$, which is in the state of general energy consumption; While the $\mathrm{NH}_{4}{ }^{+} \mathrm{N}$ load energy consumption of Longan and Siba municipal wastewater treatment plant are $30 \mathrm{~kW} \bullet \mathrm{h} / \mathrm{kg}$ and above, which is higher than the $\mathrm{NH}_{4}{ }^{+}-\mathrm{N}$ load energy consumption of domestic urban wastewater treatment plant, and is in a high energy consumption state ${ }^{[6]}$. The energy consumption per unit of wastewater treatment and the energy consumption per aerobic pollutant reflect the level of energy consumption of the operation and management of the wastewater treatment plant. However, due to the limited professional skills of the employees of the wastewater treatment plant in Luocheng municipal, the average operating load of most municipal wastewater treatment plant is low. Under the condition of low influent water quality, failure to adjust the process operating parameters, reduce the aeration intensity or shorten the aeration time in a timely manner, resulting in high energy consumption per unit of wastewater treatment and energy consumption per aerobic pollutant ${ }^{[4-7]}$.

\section{Conclusions}

\subsection{Conclusions}

(1) The wastewater treatment facilities of Luocheng municipal wastewater treatment plant have high intact rate and good operation and treatment effect, but the average operation load rate and main pollutant load rate are relatively low. The energy consumption is slightly higher than the energy consumption level of urban wastewater treatment plant in China and Guangxi, and the energy consumption per unit $\mathrm{NH}_{4}{ }^{+}-\mathrm{N}$ load is high.

(2) There are many factors affecting the evaluation of the operation and management of wastewater treatment plant in small municipal. The main reason for the low average operating load rate is the design of per capita water consumption, wastewater discharge, pipe network coverage, and wastewater network rate are high, resulting in a large scale of municipal wastewater treatment plant construction; The main pollutant load rate is low and the design high influent water concentration and large design scale are related; High energy consumption per unit of $\mathrm{COD}_{\mathrm{Cr}}$ and $\mathrm{NH}_{4}{ }^{+}-\mathrm{N}$ load is related to low operating load rate, low influent $\mathrm{COD}_{\mathrm{Cr}}$ and $\mathrm{NH}_{4}{ }^{+}-\mathrm{N}$ concentration, and lack of process operation regulation in aeration.

\section{References}

1. J.J. Meng, G.W. Cheng, L.L. Liu, et al, Journal of Guilin University of Technology, Analysis on the Construction and Operation Effect of Guangxi County-level Municipal Wastewater treatment plant, 33(1), 154-159(2013)

2. Z. Chen, G.W. Cheng, Z. Hu, et al, Journal of Guilin University of Technology, Analysis on Energy 
Consumption of Typical Municipal Wastewater treatment plant in Guangxi, 37(1), 186-190(2017)

3. F.P. Huang, G.W. Cheng, Q.C. Zou, Journal of Guilin University of Technology, Experimental Operation Effect and Energy Consumption Analysis of Municipal Wastewater treatment plant: A Case Study of Shika Municipal Wastewater treatment plant in Guigang City, 38(1), 145-149(2018)

4. Y. Jiang, W. Fu, L.H. Mao, et al, Journal of Beijing Jiaotong University, Analysis on Influence Factors of
Operation Energy Consumption of Municipal Wastewater treatment plant, 38(1), 33-37(2014)

5. F.M. Ren, R. Liang, Y. Jiang, et al, Journal of Beijing Jiaotong University, Effects of in and out water concentration and reduction on energy consumption in regional wastewater treatment plant, 38(1), 2932(2014)

6. J. Li, Guangdong University of Technology, A Study on the Soft Measurement Model of Ammonia and Operation Energy Consumption in Municipal Wastewater Treatment Works, 2018. 